\title{
To Work Alone or With Peers: Examining Smallholder Coffee Farmers' Perceptions Influencing Collective Actions
}

\author{
C. Silvert ${ }^{1}$, J. Diaz ${ }^{2}$, L. Warner ${ }^{3}$, W. Ochieng ${ }^{4}$
}

\begin{abstract}
This study examines how smallholder coffee farmers' perceptions may influence their engagement in peer mobilization and collective action. Forty smallholder coffee farmers were interviewed in the Central Highlands region of Peru using a closed-ended instrument. The sample of smallholder farmers was achieved using purposive and snowball sampling methods. Quantitative data on farmers' attitudes and aspirations regarding working with peers, autonomy, and external support as well as knowledge, skills, and behaviors pertinent to collective actions were collected and analyzed using descriptive and correlational procedures. Key findings indicate farmers perceive a need for external support, feel there are benefits of collective actions, and aspire to work with their peers. Based on the findings, it is recommended that practitioners and farmer group leaders focus training efforts on building smallholders' knowledge and skills in mobilization, encourage peer association/collective action as a source of external support, and target knowledgeable, skilled and confident farmers to lead collective actions. This study has implications to bolster support for farmer-to-farmer extension and technical assistance systems and inform the identification of leader farmers.
\end{abstract}

\section{Keywords}

association, autonomy, farmer-to-farmer, leader famer, Peru

1. Colby J. Silvert, Doctoral Student, University of Florida, 408 Rolfs Hall PO Box 110540, Gainesville, FL 32611, colby.silvert@ufl.edu, (iD https://orcid.org/0000-0003-2055-7597

2. John Diaz, Assistant Professor, University of Florida, 408 Rolfs Hall PO Box 110540, Gainesville, FL 32611, john.diaz@ufl.edu, (D) https://orcid.org/0000-0002-2787-8759

3. Laura A. Warner, Associate Professor, University of Florida, 408 Rolfs Hall PO Box 110540, Gainesville, FL 32611, Isanagorski@ufl.edu, iD https://orcid.org/0000-0003-2784-6666

4. Willis Ochieng, Doctoral Student, University of Florida, 408 Rolfs Hall PO Box 110540, Gainesville, FL 32611, wochieng@ufl.edu, (iD https://orcid.org/0000-0002-2456-480X 


\section{Introduction and Problem Statement}

Smallholder agricultural development is an investment priority for donors and international development organizations; yet many smallholder households are still food insecure and below the poverty line (Fanzo, 2017; International Fund for Agricultural Development [IFAD], 2016; United States Agency for International Development [USAID], 2019, World Bank, 2013). Several studies have indicated that smallholder farmers disproportionately face agricultural constraints impeding their emergence from poverty. For instance, smallholders often struggle to market produce and achieve commercialization due to unaffordable transaction costs and risks (e.g., transportation costs to sell small produce quantities) (Arias et al., 2013; Poulton et al., 2006). Productivity is also often diminished because smallholders cannot access key inputs such as extension and finance (Agribusiness Commercial Legal and Institutional Reform Diagnostic [AgCLIR], 2016; Arias et al., 2013). Talbot (1997) suggested smallholder farmers producing global commodity crops, such as the coffee producers in this study, confront an additional elevated risk of income loss caused by volatility of the international market. The majority of Peru's coffee producers are smallholder farmers who cultivate land plots averaging three hectares ( 7.4 acres) in size (United States Department of Agriculture Foreign Agricultural Service [USDA], 2018).

Association and cooperative organization, in which farmers work together with their peers in a formal or semi-formal capacity, may position smallholder farmers to better compete and commercialize in the globalized food system. Through the establishment of producer groups or cooperatives, smallholders commonly achieve improved negotiating power and economic benefits including higher prices (Lowitt et al., 2015; USDA, 2018). In Peru, the most established coffee farmer groups have linked farmers with finance and direct-to-consumer markets (USDA, 2018).

Unfortunately, lack of trust and social cohesion commonly discourages cooperation among smallholders (Lowitt et al., 2015). Thus, many smallholder farmers may opt to pursue most of their farm and commercialization work alone or as a household. Furthermore, while nongovernmental organizations (NGOs) often provide important external support to help smallholders establish groups (Markelova et al., 2009), NGO support may also lead to overdependence inhibiting the sustainability of collective efforts (Bebbington et al., 1996; Markelova et al., 2009). Given the nuances and documented advantages of collective actions (i.e., peer cooperation and mobilization), there is a need to better understand the potential barriers which may influence smallholders' sustainable engagement in collective actions.

\section{Theoretical and Conceptual Framework}

The conceptual framework guiding this study was structured using modified elements of the Bennett's Hierarchy evaluation model (Bennett, 1975). The component of Bennett (1975) measuring changes in knowledge, attitudes, skills, and aspirations (KASA) has been adapted for this study to frame the examination of farmers' perceptions related to working with peers and 
collective actions. The authors concentrated on these areas because researchers have more commonly studied assets, technical capacities, and market conditions affecting smallholders' mobilization and cooperation behaviors (Barham \& Chitemi, 2009; Fischer \& Qaim, 2012). Few studies, however, were found which directly measured personality and intrinsic factors that may influence farmer group mobilization and collective actions.

Fischer and Quaim (2014) explored determinants of member participation in farmer groups by comparing economic and asset-based costs and benefits, as well as evaluating individual-level trust and attitudes toward collective actions. They did not, however, measure these intrinsic variables (trust and attitudes) based on farmers' reported perceptions. Rather, trust and attitudes were inferred based on farmers' involvement in outside social groups. The researchers claimed, while these variables are important, a limitation in their study was the difficulty in measuring trust and attitudes using a structured study (Fischer \& Quaim, 2014).

Barham and Chitemi (2009), on the other hand, directly surveyed farmers on perceived trust of their farmer group members (using a Likert-type agreement scale) related to money, help in times of need, and trust more generally. Their study also explored the farmers' sense of altruism. The researchers did not discover significant relationships between trust and altruism and commercialization behaviors and outcomes (Barham \& Chitemi, 2009). These studies and the lack of additional inquiries emphasize the need for more depth and diversity in scholarly methods investigating smallholders' intrinsic factors related to engagement in collective actions, which the present study aims to address.

This study also examines how farmers' perceptions about external assistance may influence issues of over-dependence on outside support. Moreover, the authors of this study could not locate previous research exploring how collective actions relate with farmers' attitudes and aspirations regarding autonomy in their production and commercialization in contrast with receiving external support. It is important to consider that "external support" may commonly be conceptualized as outside technical assistance (TA) or finance providers but could also constitute farmers working together (i.e., forming a farmer association) who contribute to enhanced collective capacity (Silvert, 2020). Furthermore, while reliance on NGOs and other external facilitators may lead to over-dependence and discourage sustainable advancement (Bebbington et al., 1996; Markelova et al., 2009), collective actions and farmer-to-farmer mobilization could be local sources of capacity and self-reliance (Sesonga, 2018; Simpson et al., 2015). Hence, learning about potential linkages between farmers' perceptions and attitudes on outside support and working together with peers could shed new light on barriers to sustainable collective actions and commercialization.

As described by the research gaps above, this study applied variables aiming to capture farmers' attitudes and aspirations on working with peers, autonomy, and external support. These variables were examined within a framework comprised by the KASA constructs by Bennett (1975) (see Figure 1). Therefore, an additional variable measured farmers' selfreported knowledge and skills related to mobilization to appropriately align with Bennett (1975) (see Figure 1). Finally, two behavioral variables (farmer-reported frequency of 
engagement in learning or extension activities and pooling of production) were also included to examine linkages between farmers' aspirations and attitudes and related outcomes.

\section{Figure 1}

Conceptual Illustration of Factors Explored for Influencing Farmers' Collective Actions

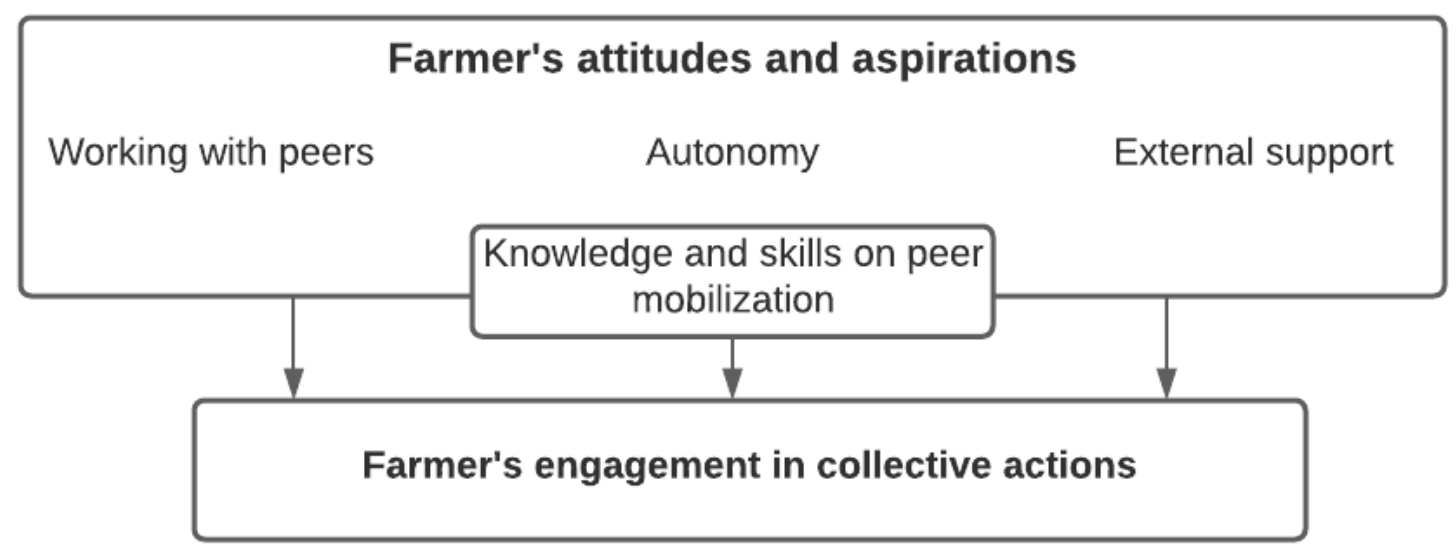

Note. This figure visualizes the intrinsic factors and knowledge and skills examined in this study for impacts on smallholder coffee farmers' engagement in collective actions. Knowledge, skills, attitudes, and aspirations modified from Bennett (1975).

\section{Purpose}

The purpose of this study was to explore smallholder coffee farmers' perceptions that may influence their engagement in mobilization and collective action. To achieve this purpose, two specific objectives guided this study:

1. Describe farmers' engagement with external support including extension, farmer association(s) and the private sector.

2. Explore how farmers' perceptions of autonomy compared to receiving outside assistance relate to their perceptions about mobilization and working with peers.

\section{Methods}

\section{Data Collection}

We partnered with the Universidad Peruana de Ciencias Aplicadas and the Shared-X company, both located in Peru, to accomplish data collection. Shared- $X$ is known as an agricultural impact company, involved in coffee production and marketing, based in Lima, Peru (Shared-X, n.d.). Peruvian agribusiness students were trained then administered the questionnaires via interviews in Spanish following best practices for cultural sensitivity (Suvedi \& Kaplowitz, 2016). Data collection efforts were not complicated by the 2020 coronavirus disease (COVID-19) 
pandemic as international travel restrictions were not yet implemented at the time of fieldwork.

Adult (18+) smallholder coffee farmers in Peru comprised the target population for this study. We achieved a sample of 40 smallholder coffee farmer participants $(N=40)$, residing in three central highland communities in the Peruvian Junín and Pasco regions. We employed multistage purposive sampling by working with Shared- $X$ to identify and recruit volunteer coffee farmers. Snowball sampling was also used in the field by asking coffee farmers to identify additional potential participants to survey. A portion of the farmers in the study had sold or had present agreements to sell coffee to Shared-X, while others produced and marketed independent of the company. Working together with Shared-X, we aimed to achieve a representative, heterogeneous sample, which resulted in $57.5 \%$ men and $42.5 \%$ women farmers ranging in age from 20 to over 60 (see Table 1). Fruit or tamales were given afterwards to volunteer farmers as tokens of gratitude for their participation.

\section{Instrumentation}

We developed the instrument to measure the variables of interest using primarily closed-ended questions and Likert-type scales modeled from previously-introduced knowledge and skills, attitudes, and aspirations (KASA) constructs by Bennett (1975). This study's variables were extracted (based on their relevance to collective actions and perceptions of autonomy and external support) from the questionnaire by (Silvert, 2020) and were treated as individual Likert-type items (Clason \& Dormody, 1994). We also included two variables measuring farmers' frequency of extension and learning, and frequency of pooling production. Additionally, farmers reported their demographics, educational level, and recent external and technical support (sources within the past one year).

Participants were asked to evaluate their level of agreement with affirmative statements related to attitudes, aspirations, and knowledge and skills on collective actions, autonomy, and external support using a five-point scale: 1 = Strongly disagree; 2 = Disagree; 3 = Neutral; 4 = Agree; and 5 = Strongly agree. We also requested farmers self-report about their extension and pooling production behaviors using a five-point response scale measuring their frequency performing the behaviors: 1 = Never; 2 = Rarely; 3 = Sometimes; $4=$ Often; $5=$ Always. All data in this study were derived from farmers' self-reported interview responses.

Before collecting data in Peru, a seven-member panel of experts reviewed the survey instrument for content and face validity. The panel included University of Florida and Peruvian extension professionals, survey design specialists, and international development researchers. Furthermore, the instrument was translated from English to Spanish and reviewed for cultural appropriateness by a team of native Spanish speakers, Peruvian extension professionals, and Shared- $X$ employees. While all variables are treated as individual items in this study, the majority of the questionnaire's original 21 KASA items comprised an index that was deemed reliable using Cronbach's alpha coefficient $(\alpha=.721)$, which is a widely-accepted indicator of internal consistency for index-based survey design (Ary et al., 2019). 


\section{Data Analysis}

We calculated frequencies for data on farmers' demographics and previous external support. Then we applied central tendency descriptive procedures (mean and standard deviation) followed by correlational analysis, using Spearman's correlation coefficient ( $r s$ ), to all of the individual Likert-type items (KASA and behavior variables) to examine direction and strength of association between pairs. Spearman's coefficient is calculated based on ranking the two variables (Schober et al., 2018).

\section{Findings}

Objective 1: Describe farmers' engagement with external support including extension, farmer association(s) and the private sector.

We documented farmers' formal education and the agriculture-related educational, extension and technical assistance sources from which they received outside support in the previous year. Only $10 \%$ of farmers reported university/tertiary-level schooling while the majority (85\%) were formally educated until the primary or secondary level (see Table 1). Technical assistance (TA) pluralism was lacking for most farmers (TA) in the previous year (see Table 2): $80 \%$ of farmers reported receiving TA from the private sector, $12.5 \%$ of farmers from government sources, and $12.5 \%$ via a farmer association or cooperative. NGOs, donor agencies, and research institutions were the least reported external support providers.

\section{Table 1}

Overview of Farmers' Demographics

\begin{tabular}{lll}
\hline Demographic & No. (n) & $\%$ \\
\hline Sex & 23 & $57.5 \%$ \\
Male & 17 & $42.5 \%$ \\
Female & & \\
Age & 7 & $17.5 \%$ \\
Aged 20 to 30 & 14 & $35.0 \%$ \\
Aged 31 to 45 & 13 & $32.5 \%$ \\
Aged 46 to 60 & 6 & $15.0 \%$ \\
Aged 61 and up & & \\
Education level & 11 & $27.5 \%$ \\
Primary & 23 & $57.5 \%$ \\
Secondary & 4 & $10.0 \%$ \\
Tertiary/university & 1 & $2.5 \%$ \\
Vocational & 1 & $2.5 \%$ \\
None & & \\
\hline
\end{tabular}

Note. $\mathrm{N}=40$ 


\section{Table 2}

Farmers' Recent Experience with Technical Assistance and Extension

\begin{tabular}{lll}
\hline External support & No. $(n)$ & $\%$ \\
\hline Technical support in previous 1 year & & \\
Yes & 34 & $85.0 \%$ \\
No & 6 & $15.0 \%$ \\
Provider/sources of support in previous 1 year & & \\
NGO or donor & 2 & $5.0 \%$ \\
Government & 5 & $12.5 \%$ \\
Private sector or input dealer & 32 & $80.0 \%$ \\
Farmer association & 5 & $12.5 \%$ \\
Research institute & 1 & $2.5 \%$ \\
\hline
\end{tabular}

Note. $\mathrm{N}=40$

Objective 2: Explore how farmers' perceptions of autonomy compared to receiving outside assistance relate to their perceptions about mobilization and working with peers.

Mean and standard deviation were the measures of central tendency applied to describe each the variables related to farmers' perceptions of collective actions, autonomy, external assistance, and self-reported knowledge and skills and behavioral frequency. Descriptive data could range from 1.00 to 5.00 based on the five-point response scale. Farmers' aspiration to learn from other successful farmers was the greatest mean (4.95) among the variables (see Table 3). Farmers' knowledge and skills in mobilization of a group of farmers produced a mean of 4.25. Farmers' perception that they do not need external support to develop their agricultural business resulted in a lower mean $(M=2.20)$. Similarly, a mean of 2.40 was reported for farmers' ability to commercialize using their own resources. The majority of variables' standard deviations (SD) ranged from 1.00 to 1.50. However, the two aspiration variables (learn from other successful farmers and grow trust with other farmers) had smaller standard deviations (.22 and .81, respectively). For the two self-reported farmer behaviors, producers reported a higher frequency of engaging in learning and extension activities $(M=$ $3.95)$ than they reported for engaging in pooling of production $(M=2.81)$ (see Table 4). 


\section{Table 3}

Farmers' Perceptions and Knowledge and Skills Central Tendency Measures

\begin{tabular}{llll}
\hline & $\mathrm{n}$ & $\mathrm{M}$ & $\mathrm{SD}$ \\
\hline Knowledge and skills: Mobilize a group of farmers & 40 & 4.25 & 1.15 \\
Working together with other farmers will help me earn more & 40 & 3.70 & 1.24 \\
I can commercialize using own resources & 40 & 2.40 & 1.39 \\
I can increase productivity using own resources & 40 & 2.75 & 1.41 \\
I don't need external support to develop ag. business & 40 & 2.20 & 1.20 \\
I have the power to negotiate for better prices & 40 & 3.38 & 1.43 \\
I can earn more money than most other coffee producers & 40 & 3.83 & 1.15 \\
I aspire to learn from other successful farmers & 40 & 4.95 & .22 \\
I aspire to work to grow trust with other farmers & 40 & 4.58 & .81 \\
\hline
\end{tabular}

Note. Variables were analyzed as individual Likert-type items using a five-point agreement response scale.

\section{Table 4}

Farmers' Collective and Extension Behaviors Central Tendency Measures

\begin{tabular}{llll}
\hline & $\mathrm{n}$ & $\mathrm{M}$ & $\mathrm{SD}$ \\
\hline Behavioral frequency: Learning or extension activities & 40 & 3.95 & 1.20 \\
Behavioral frequency: Pooling production & 36 & 2.81 & 1.69 \\
\hline
\end{tabular}

Note. Variables were analyzed as individual Likert-type items using a five-point behavioral frequency response scale.

We applied correlational analysis using Spearman's correlations to examine strength and direction of associations between pairs of the knowledge and skills, perceptions, and behavioral frequency variables in Tables 3 and 4. The correlations resulting from this analysis (see Table 5) ranged from small $(<.01)$ to large $(>.50)$ (Cohen, 1988). Power to negotiate better prices was significantly correlated with knowledge and skills to mobilize $\left(r_{s}=.37\right)$ and had inverse associations with two variables: ability to commercialize using own resources $\left(r_{\mathrm{s}}=-.31\right)$ and do not need external support to develop the agricultural business $\left(r_{\mathrm{s}}=-.36\right)$. Do not need external support to develop the farming business had its strongest inverse correlation with farmers' perception that working with other farmers will help them earn more $\left(r_{s}=-.51\right)$. Farmers' belief that they could earn more money than most other local producers showed positive correlations with two other variables: knowledge and skills to mobilize $\left(r_{s}=.38\right)$ and power to negotiate better prices $\left(r_{s}=.40\right)$. On the other hand, the earn more money than most other producers variable had an inverse association with perceived ability to increase productivity using own resources $\left(r_{\mathrm{s}}=-.44\right)$.

Finally, there were two significant correlations, both negative, with the two behavior variables. Farmers' frequency of engagement in learning and extension associated inversely with do not need external support to develop the agricultural business $\left(r_{s}=-.38\right)$. Frequency of farmer- 
reported pooling of production showed an inverse correlation with perceived ability to commercialize using own resources $\left(r_{s}=-.40\right)$.

\section{Table 5}

Correlation Matrix of Farmers' Perceptions of Collective Actions and External Assistance and Farmers' Collective and Extension Behaviors

\begin{tabular}{|c|c|c|c|c|c|c|c|c|c|c|c|}
\hline & 1 & 2 & 3 & 4 & 5 & 6 & 7 & 8 & 9 & 10 & 11 \\
\hline $\begin{array}{l}\text { Knowledge and } \\
\text { skills: Mobilize a } \\
\text { group of farmers }\end{array}$ & - & & & & & & & & & & \\
\hline $\begin{array}{l}\text { Working together } \\
\text { with other farmers } \\
\text { will help me earn } \\
\text { more }\end{array}$ & .25 & - & & & & & & & & & \\
\hline $\begin{array}{l}\text { I can commercialize } \\
\text { using own } \\
\text { resources }\end{array}$ & -.30 & -.22 & - & & & & & & & & \\
\hline $\begin{array}{l}\text { I can increase } \\
\text { productivity using } \\
\text { own resources }\end{array}$ & -.28 & -.14 & $.46^{* *}$ & - & & & & & & & \\
\hline $\begin{array}{l}\text { I don't need external } \\
\text { support to develop } \\
\text { ag. business }\end{array}$ & -.09 & $-.51^{* *}$ & $.34^{*}$ & $.39^{*}$ & - & & & & & & \\
\hline $\begin{array}{l}\text { I have the power to } \\
\text { negotiate for } \\
\text { better prices }\end{array}$ & $.37^{*}$ & .30 & $-.31^{*}$ & -.21 & $-.36^{*}$ & - & & & & & \\
\hline $\begin{array}{l}\text { I can earn more } \\
\text { money than most } \\
\text { other coffee } \\
\text { producers }\end{array}$ & $.38^{*}$ & .17 & -0.22 & $-.44^{* *}$ & -.18 & $.40^{*}$ & - & & & & \\
\hline $\begin{array}{l}\text { I aspire to learn from } \\
\text { other successful } \\
\text { farmers }\end{array}$ & .12 & .01 & .01 & .06 & -.03 & -.18 & -.13 & - & & & \\
\hline $\begin{array}{l}\text { I aspire to work to } \\
\text { grow trust with } \\
\text { other farmers }\end{array}$ & $.33^{*}$ & .29 & .20 & $-.34^{*}$ & $-.33^{*}$ & .18 & $.46^{* *}$ & .08 & - & & \\
\hline $\begin{array}{l}\text { Behav. frequency: } \\
\text { Learning or } \\
\text { extension activities }\end{array}$ & .23 & .09 & -.21 & -.16 & $-.38^{*}$ & .13 & .30 & .06 & .19 & - & \\
\hline $\begin{array}{l}\text { Behav. frequency: } \\
\text { Pooling production }\end{array}$ & .05 & .26 & $-.40^{*}$ & -.10 & -.02 & .07 & -.12 & -.13 & -.14 & -.17 & - \\
\hline
\end{tabular}




\section{Conclusions, Discussion, and Recommendations}

Smallholder farmers can achieve numerous economic benefits through collective actions and the mobilization of peers (Arias et al., 2013; Campos et al., 2005; USDA, 2018). Three key conclusions emerge from this study to understand the intrinsic factors that may influence smallholders' collective actions. First, findings suggest smallholder farmers perceive important benefits from boosting their knowledge and skills in mobilization. Second, results imply smallholders consider collection action with peers an important source of external support, which should be distinguished from other types of external support. Finally, the data indicate farmers with knowledge and skills and confidence in their abilities aspire to work to build trust with their peer farmers.

The correlations between farmers' knowledge and skills to mobilize and their perceived negotiating and earning powers suggest farmers believe their positioning to market could be enhanced via capacities related to collective actions. Improved marketing opportunities could benefit smallholders through increased incomes. Although knowledge and skills may not always correspond with behaviors, this conclusion is corroborated by previous research which suggests ability to mobilize and pursue collective actions contributes to greater negotiating power and returns (Lowitt et al., 2015; USDA, 2018). It should be noted that structural and collective considerations, not assessed in this study, may also influence marketing power. For instance, the number of peers and their commitment toward mobilization could determine produce quantities and impact leverage over marketing opportunities (Campos et al., 2005).

Inverse associations between farmers' aspiration to grow trust with peers and their perceptions toward autonomy in their agricultural activities imply farmers' perceived need for external support could potentially be fulfilled through collective action. Additionally, analysis of the behavioral variables indicates farmers who engage in pooling produce feel they need commercialization assistance. These findings are important because research indicates assistance from external organizations and actors may negatively decrease self-reliance and cause over-dependence (Bebbington et al., 1996; Markelova et al., 2009; Silvert, 2020). However, if forms of external assistance are distinguished (e.g., temporary donor projects versus a local farmer association), farmers' perceived need for outside support could be channeled toward potentially more sustainable, local sources of capacity.

The final conclusion infers the characteristics of smallholder farmers who may lead among peers in the pursuit of collective actions. Correlational results suggest farmers who are knowledgeable and skilled in mobilization aspire to grow trust with peers. The positive association between perceived earning ability and aspiration to build trust also indicates farmers' confidence and self-efficacy may be perquisites to collective action. These findings could inform the identification of leader farmers to champion mobilization and collective actions. Furthermore, this suggests capacity building around collective actions may be an important starting point to increase farmers' motivation to pursue working with their peers. 
Leader farmer approaches are commonly employed in developing contexts to facilitate peer-topeer mobilization and learning (Sesonga, 2018; Simpson et al., 2015).

This study provided new insights to understand smallholders' perceptions related to collective actions. Refinements and expansion of the variables and instrumentation, to potentially develop multi-variable constructs, are recommended for future inquiries. This study was limited by its relatively small sample size. For future explorations, the power of analyses should be increased using a larger sample (Israel, 2009).

Based on this study's findings, we recommend practitioners and farmer group leaders focus training efforts on building smallholders' knowledge and skills in mobilization, encourage peer association/collective action as a source of external support, and target knowledgeable, skilled and confident farmers to lead collective actions. When possible, opportunities should be explored for farmers' perceived need for outside assistance to be fulfilled by peer, communitybased groups rather than external organizations' (e.g., NGOs and donor programs).

Practitioners and farmer leaders can learn from examples of peer-to-peer agricultural extension systems, both formal and informal, which have become common in development contexts (Simpson et al., 2015). Experiential exchange visits and farmer-led field days are useful techniques to demonstrate the operations and benefits of collective actions for interested farmers, and research suggests farmers often learn more from fellow farmers than external practitioners (Suvedi \& Kaplowitz, 2016; Van den Ban \& Hawkins, 2002). Finally, training and targeting more innovative farmers, such as those with technical knowledge and skills and greater self-efficacy, may play a crucial role in farmer-to-farmer systems to set trends for other farmers and contribute to disseminating improved behaviors (Rogers, 2003; Simpson et al., 2015).

\section{Acknowledgements}

Support to conduct fieldwork for this study was provided by partners in Peru from the Universidad Peruana de Ciencias Aplicadas and the Shared-X company and especially these individuals: Ivan Loyola, Dr. Raul Injoque, Joel Barboza, Rosalina Cuchca, and Jimy Lovato. The authors are also thankful to Vanessa Campoverde and Francisco Rivera for their review and translation of the survey instrument.

\section{References}

Agribusiness Commercial Legal and Institutional Reform Diagnostic. (2016). Sierra Leone final report. International Development Group LLC.

Ajzen, I. (1991). The theory of planned behavior. Organizational Behavior and Human Decision Processes, 50(2), 179-211. https://doi.org/10.1016/0749-5978(91)90020-T.

Arias, P., Hallam, D., Krivonos, E., \& Morrison, J. (2013). Smallholder integration in changing food markets. Food and Agriculture Organization of the United Nations. http://www.fao.org/3/i3292e/i3292e.pdf 
Ary, D., Jacobs, L. C., Irvine, C. K. S., \& Walker, D. (2019). Introduction to research in education (10th ed.). Cengage Learning.

Barham, J., \& Chitemi, C. (2009). Collective action initiatives to improve marketing performance: Lessons from farmer groups in Tanzania. Food Policy, 34(1), 53-59. https://doi.org/10.1016/i.foodpol.2008.10.002

Bebbington, A., Quisbert, J., \& Trujillo, G. (1996). Technology and rural development strategies in a small farmer organization: Lessons from Bolivia for rural policy and practice. Public Administration and Development, 16(3), 195-213. https://doi.org/10.1002/(SICI)1099162X(199608)16:3<195::AID-PAD879>3.0.CO;2-2

Bennett, C. (1975). Up the hierarchy. Journal of Extension, 13(2), 7-12. https://www.joe.org/joe/1975march/1975-2-a1.pdf

Campos, M., Francis, M., \& Merry, F. (2005). Stronger by Association: Improving the understanding of how forest-resource based SME associations can benefit the poor. Instituto de Pesquisa Ambiental da Amazônia. https://pubs.iied.org/pdfs/13513IIED.pdf?

Clason, D. L., \& Dormody, T. J. (1994). Analyzing data measured by individual Likert-type items. Journal of Agricultural Education, 35(4), 31-35. https://doi.org/10.5032/jae.1994.04031

Cohen, J. (1988). Statistical power analysis for the behavioral sciences (2nd ed.). Lawrence Erlbaum.

Fanzo, J. (2017). From big to small: The significance of smallholder farms in the global food system. The Lancet Planetary Health, 1(1), e15-e16. https://doi.org/10.1016/S25425196(17)30011-6

Fischer, E., \& Qaim, M. (2012). Linking smallholders to markets: Determinants and impacts of farmer collective action in Kenya. World Development, 40(6), 1255-1268.

https://doi.org/10.1016/j.worlddev.2011.11.018

Fischer, E., \& Qaim, M. (2014). Smallholder farmers and collective action: What determines the intensity of participation?. Journal of Agricultural Economics, 65(3), 683-702.

https://doi.org/10.1111/1477-9552.12060

Frey, B. B. (2016). There's a stat for that! What to do \& when to do it. Sage Publications.

International Fund for Agricultural Development. (2016). Rural development report 2016:

Fostering inclusive rural transformation.

https://www.ifad.org/documents/38714170/39155702/Rural+development+report+2016.pdf/ 347402dd-a37f-41b7-9990-aa745dc113b9 
Israel, G. D. (2009). Determining sample size. Agricultural Education and Communication, Program Evaluation and Sampling. University of Florida Cooperative Extension Electronic Data Information Source, PEOD6.

Lowitt, K., Hickey, G. M., Saint Ville, A., Raeburn, K., Thompson-Colón, T., Laszlo, S., \& Phillip, L. E. (2015). Factors affecting the innovation potential of smallholder farmers in the Caribbean community. Regional Environmental Change, 15(7), 1367-1377.

https://doi.org/10.1007/s10113-015-0805-2

Markelova, H., Meinzen-Dick, R., Hellin, J., \& Dohrn, S. (2009). Collective action for smallholder market access. Food Policy, 34(1), 1-7. https://doi.org/10.1016/i.foodpol.2008.10.001

Poulton, C., Kydd, J., \& Dorward, A. (2006). Overcoming market constraints on pro-poor agricultural growth in Sub-Saharan Africa. Development Policy Review, 24(3), 243-277. https://doi.org/10.1111/j.1467-7679.2006.00324.x

Rogers, E. M. 2003. Diffusion of innovations. (5th ed.). Simon and Schuster.

Schober, P., Boer, C., \& Schwarte, L. A. (2018). Correlation coefficients: Appropriate use and interpretation. Anesthesia \& Analgesia, 126(5), 1763-1768.

https://doi.org/10.1213/ANE.0000000000002864

Sesonga, J. P. (2018, June 5). Follow the leader. World Food Programme. https://insight.wfp.org/follow-the-leader-c34ed51f550

Shared-X. (n.d.). Farm share impact. https://www.shared-x.com/

Silvert, C. (2020) Building self-reliance: An evaluation framework for smallholder farmers' transition to commercialization. [Unpublished master's thesis]. University of Florida

Simpson, B. M., Franzel, S., Degrande, A., Kundhlande, G., \& Tsafack, S. (2015). Farmer-tofarmer extension: Issues in planning and implementation. Modernizing Extension and Advisory Services. https://meas.illinois.edu/wp-content/uploads/2017/02/MEAS-TN-Farmer-to-FarmerSimpson-et-al-May-2015.pdf

Suvedi, M., \& Kaplowitz, M. (2016). What every extension worker should know. Modernizing Extension and Advisory Services. https://meas.illinois.edu/wp-content/uploads/2015/04/MEAS2016-Extension-Handbook-Suvedi-Kaplowitz-2016 02 15.pdf

Talbot, J. M. (1997). Where does your coffee dollar go?: The division of income and surplus along the coffee commodity chain. Studies in Comparative International Development, 32(1), 56-91. https://doi.org/10.1007/BF02696306 
United States Agency for International Development. (2019). Agriculture and food security. https://www.usaid.gov/what-we-do/agriculture-and-food-security

United States Department of Agriculture Foreign Agricultural Service. (2018). Peru's Coffee production continues recovering.

https://apps.fas.usda.gov/newgainapi/api/report/downloadreportbyfilename?filename=Coffee \%20Annual Lima Peru 5-9-2018.pdf

Van den Ban, A. W., \& Hawkins, H. S. (2002). Agricultural extension (2nd ed.). CBS Publishers and Distributors.

World Bank. (2013). Agriculture action plan 2013-2015. http://documents.worldbank.org/curated/en/331761468152719470/pdf/779110WP0Ag0Ac0th an0the0Board0paper.pdf

(C) 2021 by authors. This article is an open access article distributed under the terms and conditions of the Creative Commons Attribution license (http://creativecommons.org/licenses/by/4.0/). 